\title{
Un momento relevante en la historia de la crítica artística latinoamericana de la segunda mitad del siglo XX: el simposio de Austin (1975)
}

José Luis de la Nuez Santana

Universidad Carlos III de Madrid

nogal@hum.uc3m.es - https://orcid.org/0000-0003-2823-0070

Fecha recepción 15.05.2019 / Fecha aceptación 03.12.2019

\section{Resumen}

Este texto está centrado en el análisis de los contenidos de los debates del simposio de arte y literatura celebrado en Austin, Estados Unidos, en octubre de 1975. El propósito de dicho análisis persigue contextualizar culturalmente las discusiones habidas y distinguir las distintas orientaciones críticas en el mudo artístico, tanto entre latinoamericanos y estadounidense como entre los propios artistas y críticos latinoamericanos.

\section{Palabras clave}

Arte latinoamericano contemporáneo, crítica de arte latinoamericana, identidad, arte y política, vanguardia.

\section{Abstract}

This paper focuses on the content analysis of the debates on Latin American art and literature held at the Austin symposium, United States, in October 1975. The purpose of this study is to contextualize culturally the debates and to distinguish the different critical orientations in the artistic world, both among Latin Americans and Americans and among the Latin American artists and critics themselves.

\section{Keywords}

Latin American contemporary art, Latin American art criticism, identity, art and politics, avant-garde 



\section{Introducción}

Una aproximación a la trayectoria del pensamiento crítico en el arte latinoamericano, por muy elemental que sea, revela una evolución muy significativa en la segunda mitad del siglo XX; evolución que se constata tanto en el protagonismo creciente de algunos de sus principales representantes como en el enriquecimiento metodológico que las propuestas de estos sugieren. La perspectiva histórica ha permitido una mayor profundización en estos temas en diversos estudios, como los impulsados por el ambicioso proyecto «Los estudios de arte desde América Latina: temas y problemas» ${ }^{1}$. De manera más específica merecen destacarse aportaciones como las de Guadalupe Álvarez ${ }^{2}$ o Fabiana Serviddio ${ }^{3}$, entre otras. Por su parte, los trabajos de Joaquín Barriendos ${ }^{4}$ tratan de resituar el alcance de esta crítica desde una perspectiva que establece un contraste inevitable con los nuevos planteamientos que la realidad de la globalización ha determinado. A su vez, la sistematización de la información en diversos libros y catálogos o la apertura de una base de datos de documentos como la ICAA de la universidad de Houston abren un campo enorme a la investigación de este mundo del pensamiento crítico.

La década de los setenta del siglo pasado se manifiesta como un periodo clave en el proceso de visualización de la crítica artística latinoamericana, en el sentido de una superación de los límites nacionales de su actividad y su implicación en un escenario internacional, esencialmente americano. Desde luego, algunos críticos, como Marta Traba o Damián Bayón, ya habían adelantado en algunos de sus trabajos el interés por un estudio

1. Auspiciados por la Fundación Rockefeller para las Humanidades (1996), la UNAM (1997) y el Getty Grant Program (1999-2003).

2. Vid. G. Álvarez de Araya Cid, “Temas de la crítica: tratamientos del origen cultural, la identidad y la transculturación en la crítica de arte latinoamericana entre 1930 y 1975”, Figuraciones, 10, 2012.

3. Sobre todo, vid. F. Serviddio, Arte y crítica en Latinoamérica durante los años setenta, Buenos Aires, 2013.

4. Vid. J. Barriendos, Geoestética y Transculturalidad. Fundació Espais d’Art Contemporani, Barcelona: 2007; P “Decolonizing Western Geographical Thinking Mobility, Internationalism, Global Art”, en. Parcerisas y J. Barriendos, Global Circuits: The Geography of Art and the New Configurations of Critical Thought, Barcelona, 2011, 93-103. También su tesis doctoral La idea del arte latinoamericano, Universidad de Barcelona, 2013 (Consultable en el repositorio de la Universidad de Barcelona http://diposit.ub.edu/dspace/ bitstream/2445/41383/1/JBR_TESIS.pdf) 
que abarcase la pluralidad de la actividad artística del subcontinente ${ }^{5}$, a la par que sus trayectorias biográficas reafirmaban esta vocación internacional, pero lo que queremos destacar aquí es que es en este momento cuando se abren espacios de debate que van a poner de relieve la diversidad de posturas críticas, las sintonías y las discrepancias entre los participantes. El simposio de Quito ${ }^{6}$, organizado por la UNESCO (junio de 1970), abre este periodo de puesta al día en la discusión de los pensamientos críticos y se ve continuado por el de Austin ${ }^{7}$ (octubre de 1975), el Primer Encuentro Iberoamericano de Críticos de Arte y Artistas Plásticos ${ }^{8}$ (Caracas, junio de 1978) y el simposio asociado a la I Bienal Latinoamericana de São Paulo (noviembre-diciembre de 1978) ${ }^{9}$. En el marco de la celebración de estos encuentros confluyen críticos con recorridos profesionales de intensidad diversa. A este respecto, las trayectorias críticas de Marta Traba, Damián Bayón y, en mayor medida, Jorge Romero Brest, maestro de los dos anteriores, estaban más que asentadas en los setenta; con mayor motivo en el caso del brasileño Mario Pedrosa, mientras que otros, como Juan Acha, Frederico Morais, Aracy Amaral, Rita Eder o Jorge Alberto Manrique, tendrán mayor repercusión a partir de ahora. Lo mismo puede decirse de Jorge Glusberg y García Canclini, aunque la actividad crítica de este último no deje de ser solo una faceta de su variado trabajo intelectual. Algunos, como Mirko Lauer o el ya citado García Canclini, pueden considerarse como intelectuales puente con la nueva generación de críticos que surge en los ochenta, en el contexto de la crisis de la modernidad y la irrupción de la postmodernidad (Gerardo Mosquera, Nelly Richard, Ticio Escobar, Ivo Mesquita, entre otros).

Dirigimos la atención hacia el caso concreto del simposio de Austin, toda vez que este acontecimiento muestra un perfil bastante singular, debido a la concatenación de una serie de circunstancias que merecen ser resaltadas. En primer lugar, que el evento se desarrollase en los Estados Unidos, lo cual trajo consigo la participación notoria de historiadores y críticos procedente de ese país (Dore Ashton, Jacqueline Barnitz, Stanton Catlin L., Donald Goodall y Terence Grieder). Desde luego, no puede separarse esta particularidad del hecho

5. Vid. M. Traba, La pintura nueva en Latinoamérica, Bogotá, 1961; D. Bayón, Aventura plástica de Hispanoamérica, México, 1974.

6. Aunque no se han editado las actas de esta reunión, Damián Bayón publicó un libro en 1974 que recogía la estructura temática que había servido de guía para la realización del evento. Vid. D. Bayón, América Latina en sus artes, Siglo XXI editores, Madrid/México/Buenos Aires, 1974.

7. Las ponencias y debates de este simposio se recogen literalmente en D. Bayón, El artista latinoamericano y su identidad, Caracas, 1977. En algunos casos, se reproducen las intervenciones directas (que fueron grabadas), pero no el texto escrito íntegro.

8. Las ponencias presentadas este congreso no están editadas, pero pueden consultarse los textos en la base de datos ICAA de la Universidad de Houston, Estados Unidos.

9. No existe edición de los textos de la crítica de este evento, pero a él se refieren J. Acha ("Las bienales en América Latina de hoy", Re-vista del arte y la arquitectura en América Latina de hoy, 2, 6, 1981, 14-16); F. Morais (“Apêndice: I Bienal Latinoamericana de São Paulo", en Artes Plásticas na América Latina: do transe ao transitorio, Civilização Brasileira, 1979, 62-65), y A. Amaral, ("A Bienal Latino-americana ou o desvirtuamento de uma iniciativa 1978", en Arte e meio artístico: entre a feijoada e o x-burger, Livraria Nobel, São Paulo, 1982, 296-301). 
de que el arte latinoamericano estaba adquiriendo de nuevo en el país norteamericano un interés sin precedentes desde la época del muralismo mexicano. Además, la universidad anfitriona, la University of Texas (Austin), ya albergaba en ese momento la colección de arte latinoamericano más importante de los Estados Unidos ${ }^{10}$. Pero fue la intervención de un importante plantel de críticos latinoamericanos bien conocidos en esos momentos (Juan Acha, Aracy Amaral, Damián Bayón, Rita Eder, Jorge Alberto Manrique, Frederico Morais, Jacinto Quirarte, Carlos Rodríguez Saavedra, Kazuya Sakai y Marta Traba) lo que le dio carácter extraordinario al encuentro. Con todo, algunas ausencias resultaron llamativas. Nos referimos sobre todo al argentino Jorge Romero Brest ${ }^{11} \mathrm{y}$ al brasileño Mario Pedrosa. Por otro lado, el simposio se vio acompañado de una exposición organizada por la revista mexicana Plural $^{12}$, dirigida por Octavio Paz, algo que provocó en el propio debate alusiones de gran interés. A esto hay que añadir la participación en las distintas sesiones de artistas ya consagrados en esa época, como los mexicanos Tamayo, José Luis Cueva, Helen Escobedo y Manuel Felguérez; el colombiano Leonel Góngora, el venezolano Alejandro Otero, el argentino y también crítico Kazuya Sakai y el peruano Fernando de Szyszlo.

\section{Críticos y artistas latinoamericanos en el debate}

El simposio de Austin supuso para la crítica latinoamericana un momento muy esclarecedor por lo que se refiere al debate de temas esenciales que estaban en el marco de las grandes preocupaciones del arte del momento. El organizador, Damián Bayón, había propuesto para guiar las discusiones una batería de preguntas que fueron las siguientes:

1. ¿Existe en el arte latinoamericano contemporáneo como una expresión distinta? Si existe, ¿en qué términos tiene lugar?

2. ¿Puede el artista latinoamericano producir independientemente de los intereses extranjeros?

3. ¿Qué modelos operativos tiene el artista latinoamericano a su disposición: corrientes internacionales, movimientos indígenas o cualquier otro recurso?

10. Colección iniciada por John Goodall, que había pasado a ser director del Museo de la Universidad de Texas en 1959.

11. En relación con su ausencia en el simposio de Austin, J. Romero Brest escribe "El artista latinoamericano y su identidad", Plástica, 2, 1978, 26-30.

12. La muestra, que llevaba el título «Doce artistas latinoamericanos» (28 de septiembre- 2 de noviembre de 1975), estaba integrada por obras de Gunther Gerzso, Manuel Felguérez, Vicente Rojo, Sergio de Camargo, Cruz-Díez, Luis Tomasello, Marcelo Bonevardi, Francisco Toledo, Fernando de Szyszlo, Brian Nissen, Roger von Guten y Edgar Negret. En la organización de la muestra participaron activamente tanto Damián Bayón como Kazuya Sakai, ligados los dos a la revista Plural. La exposición debe considerarse como un acontecimiento dentro del Festival de las artes de 1975 de la Facultad de Bellas Artes de la Universidad de Texas, Austin. Vid. D. B. Goodall, “Exposición Plural: Doce artistas latinoamericanos, Plural, 50, $1975,93$. También sobre la exposición escribió Damián Bayón un extenso artículo. Vid. Damián Bayón, “Crítica y autocrítica”, Plural, 53, 1976, 27-32. 
4. ¿Hasta qué punto el artista latinoamericano responde a sus circunstancias inmediatas: comunidad, recursos plásticos o cualquier otra circunstancia?

5. ¿Es cierta la queja de que la falta de crítica artística en América Latina obliga al artista a buscar respuesta en otros medios? ${ }^{13}$

$\mathrm{Al}$ analizar los contenidos de los debates del simposio encontramos dos temas que se ajustan inequívocamente a estos puntos establecidos de manera previa: la cuestión de la identidad en el arte latinoamericano contemporáneo y el papel y la naturaleza de la crítica de arte en el subcontinente. Hay, finalmente, un tercero que no fue acordado inicialmente pero que, de manera espontánea, apareció en las sesiones: la relación entre arte y política, enfocada fundamentalmente al caso cubano.

El inicio de las sesiones del simposio se vio precedido por la lectura de un texto de Octavio Paz, director de Plural, revista involucrada, como se ha dicho, en la organización de la exposición del mismo nombre. Además, tanto Bayón, como Juan Acha y Jorge Alberto Manrique formaban parte del elenco de colaboradores de esta publicación. No hace falta insistir, por otro lado, en la importancia que la crítica tenía en los escritos de Octavio Paz ${ }^{14}$. Aunque el texto de este estaba claramente dirigido a la sección literaria del simposio y no a la artística, hay, sin embargo, algunas afirmaciones generales que van más allá de esta especificidad y apuntan a una manera de entender la cultura latinoamericana que enlaza, como se verá, con algunos de los asuntos más controvertidos que se airearon en la reunión de Austin. Una de ellas subraya la filiación de dicha cultura al mundo occidental, algo que para Paz resulta tan evidente como censurable es también el querer vincularla a una dimensión tercermundista: «...por la historia y la cultura pertenecemos a Occidente, no a ese nebuloso Tercer Mundo del que hablan los economistas y los políticos. Somos un extremo de Occidente, un extremo excéntrico y disonante» ${ }^{15}$. Hablar, por tanto, de crítica en América Latina tenía todo su sentido; más allá de las carencias de esta, algo motivado no solamente por la ausencia en la cultura hispánica de sólidos fundamentos filosóficos, sino también por la distancia con la que se vivieron en su momento la cultura ilustrada y las revoluciones burguesas. Las consecuencias de esta falta de sintonía con la evolución cultural de otros países europeos resultaban para el autor mexicano bien concluyentes:

Conocemos la sátira, la rebeldía, el humor y la rebeldía heroica, pero no la crítica en el sentido recto de la palabra. Por eso tampoco conocemos la tolerancia, fundamento de la civilización política, ni la verdadera democracia, que consiste en la libertad y que reposa en el respeto a los disidentes y a los derechos de las minorías. Nuestros pueblos viven entre los espasmos de la rebeldía y el estupor de la pasividad ${ }^{16}$.

13. D. Bayón, El artista latinoamericano..., op. cit., 26.

14. Para una visión integral de esta contribución del autor mexicano, vid. O. Paz, Obras completas, t. IV, Barcelona, 2001.

15. O. Paz, "Palabras al simposio", en Damián Bayón, El artista latinoamericano y su..., op. cit., 23.

16. O. Paz, "Palabras..., op. cit., 24. 
Había además una denuncia por parte del autor mexicano que apuntaba directamente a las consecuencias negativas que había traído la difusión de las ideologías políticas contemporáneas, calificadas por él como «formas inferiores del instinto religioso», frente a las cuales «muchos intelectuales latinoamericanos han abdicado. No han adorado, como los de otras épocas, al "becerro de oro", sino al toro de la violencia obtusa y del poder intolerante» ${ }^{17}$. Lo cierto es que, en ningún caso, la postura de Paz en este sentido, que apunta con mucha probabilidad al marxismo, aunque no de manera exclusiva seguramente, tuvo un reflejo reconocible entre los críticos participantes en el evento de Austin, ni siquiera cuando se trató del caso cubano. Al contrario, no resulta difícil encontrar simpatías más o menos confesadas, o asumidas de manera implícita, frente a lo que había sido la experiencia chilena frustrada o la castrista en marcha.

\section{El asunto de la identidad}

Sin duda alguna, la identidad fue el tema más debatido en el simposio, que se abre justamente con la lectura de la ponencia de Juan Acha con definiciones que tendrán cierta repercusión polémica. Conviene precisar que Acha no era en estos momentos todavía el crítico de referencia de años posteriores, por más que fuera ya una figura conocida, colaborador en Plural. Será en la segunda mitad de los setenta y década siguiente ${ }^{18}$, incluso en los noventa ${ }^{19}$, cuando aparezcan los principales textos dedicados al tema de la identidad latinoamericana, en un momento, por cierto, en el que las visiones totalizantes de la crítica estaban más que cuestionadas. En su intervención en Austin, parte de la certeza de que no existen instrumentos adecuados para encontrar y definir las claves de una identidad artística latinoamericana. Por eso, «...falta construir modelos conceptuales que comprendan y nos hagan comprender lo que somos y a la vez el hecho de que queremos ser otros (...) Construir modelos que comprendan y nos hagan comprender la coexistencia de lo latinoamericano en Tamayo y en Soto, por ejemplo» ${ }^{20}$. Más adelante, Acha quiso precisar que, a diferencia de lo que opinaban otros críticos como Marta Traba o Bayón, no se trataba tanto de la búsqueda de una identidad (algo que se da por supuesto que existe), «sino de la búsqueda de la autoconcientización de nuestra identidad, que no es la europea o de tipo occidental, o sea unitaria, sino plural $»^{21}$. La idea de Acha contó con la simpatía de algunos críticos, pero también con detractores. Así, si bien Bayón la veía como una propuesta afortunada y clarificadora, Rodríguez Saavedra expresó

17. O. Paz, "Palabras..., op. cit., 24.

18. Vid. J. Acha, "La necesidad latinoamericana de un pensamiento visual independiente", en Ensayos y ponencias latinoamericanistas, Caracas, 1984.

19. Vid. J. Acha, Aproximaciones a la identidad latinoamericana, México, 1996.

20. J. Acha, "Primera sesión (27 de octubre de 1975)", en Damián Bayón, El artista latinoamericano..., op. cit., 27.

21. J. Acha, "Primera..., op. cit, 43. 
su desavenencia, pues se podía entender «la construcción del modelo conceptual como un programa de trabajo dictado al artista ${ }^{22}$.

Cuando, en la lectura de su ponencia, Carlos Rodríguez Saavedra quiere fijar los rasgos más significativos de un arte latinoamericano «maduro, auténtico y profundo», se distancia del indigenismo, que considera desvitalizado y ornamental, a pesar del «vago sentimiento social que transmite»; también de ese otro arte que imita adocenadamente las corrientes occidentales. Hay, por el contrario, otros artistas (Tamayo, Obregón, Lam, Szyszlo...) «que han superado el formalismo representativo mediante la creación experimental de un nuevo lenguaje (...) Este es un arte exonerado de la sujeción pasadista, liberado del colonialismo occidental y simultáneamente responsable de la realidad latinoamericana ${ }^{23}$. Al establecer esta genealogía de la creación latinoamericana contemporánea en clave de autenticidad, el crítico peruano incidía en un espacio común de acuerdo compartido con otros críticos, como Marta Traba y Damián Bayón. Más adelante aclarará que no se trataba, en todo caso, de rechazar enteramente los valores de la cultura occidental, pues esto equivaldría a «renunciar a los instrumentos de liberación que en todo orden - y creo que también en el orden estético a través de las vanguardias por su aspecto creativo - podemos obtener ${ }^{24}$. Era este un subrayado sumamente interesante porque incidía en uno de los temas centrales del debate contemporáneo al que había aludido Octavio Paz y que quedaba aparentemente cuestionado en las propuestas de otros como era el caso de Marta Traba y su rechazo a las últimas vanguardias.

Fue precisamente Marta Traba quien polarizó la atención del simposio con la lectura de su ponencia y posteriores intervenciones. Como ocurría con Damián Bayón, Traba acumulaba ya una trayectoria larga y rica como crítica. Pocos años antes de la celebración del encuentro de Austin había dado a conocer dos libros importantes: Arte Latinoamericano Actual (1972) y Dos décadas vulnerables en las artes plásticas latinoamericanas (1973), su obra más estudiada, donde da a conocer por vez primera su concepto de «resistencia» aplicado al mundo del arte. El espíritu de Marta Traba, incisivo y polémico, generó muchísimas respuestas, fueran estas de rechazo o adhesión. En la exposición de su ponencia fue desgranando las líneas maestras de su pensamiento crítico, que iban encaminadas a denunciar tanto la vacuidad de las últimas tendencias vanguardistas como la dependencia de la cultura artística latinoamericana de los centros hegemónicos y las consecuencias de todo ellos. Su afirmación inicial no deja lugar a la duda:

Nosotros NO EXISTIMOS ${ }^{25}$ ni como expresión artística distinta, ni tampoco como expresión artística, fuera de los límites de nuestro continente (...) Teniendo en cuenta que el proceso del arte moderno y actual ha sido fraguado en dos metrópolis, primero en París y luego Nueva York, y ha servido incondicionalmente a un proyecto imperialista destinado a descalificar las provincias culturales y a unificar los productos artísticos en un conjunto engañosamente homogéneo

22. C. Rodríguez Saavedra, "Primera..., op. cit., 44.

23. C. Rodríguez Saavedra, "Primera..., op. cit., 32.

24. C. Rodríguez Saavedra, "Segunda sesión (28 de octubre)", op. cit., 90.

25. La mayúscula viene en el texto original. 
que tiende a fundar una cultura planetaria, nuestra existencia artística ni siquiera se plantea como una probabilidad ${ }^{26}$.

El rechazo de Traba a los lenguajes modernos más recientes, exponentes según su criterio del «terrorismo de las vanguardias», iba acompañado de un diagnóstico de la realidad artística latinoamericana que se explicaba por la relación de los artistas con estos movimientos metropolitanos. Y es que, si bien algunos habían optado por la identificación plena con esos lenguajes vinculados al consumismo y alejados de cualquier propuesta de ficción, otros sí habían querido establecer una distancia, «al advertir la estafa, distorsión y liquidación del arte que se programaba ${ }^{27}$. En este último caso, se trataba de una postura que permitía identificarla con una "cultura de la resistencia» que tenía sus primeros ejemplos en la generación de los iniciadores de la modernidad latinoamericana (Torres-García, Reverón, Matta...) y su continuidad en creadores contemporáneos como Szyszlo, Armando Morales y José Luis Cuevas, entre otros. En el análisis de Traba, por lo demás, se buscaba establecer una clara vinculación entre proyecto artístico y situación socioeconómica, algo que hacía aún más polémica su postura crítica. Al fin y al cabo, los artistas de la "cultura de la resistencia» respondían con su trabajo a un medio bien distinto del tecnológico y desarrollado Primer Mundo: «Nuestras sociedades son mayoritariamente pre-tecnológicas, agrarias y corresponden a una economía de subdesarrollo. El subdesarrollo cultural, al dejar a los artistas librados a sus propias fuerzas, les ha permitido, sin embargo, defenderse mejor ${ }^{28}$. Esta asociación entre subdesarrollo y arte resistente fue, no obstante, criticada fuertemente por algunos de los críticos asistentes, como es el caso de la mexicana Rita Eder, para quien la idea de un arte diferenciado basado en una figuración sofisticada asociada a unas condiciones económicas podría suponer una limitación en la libertad del artista. Esto es, «detener la imaginación y el proceso creativo para establecer un modelo de creación o una conducta de creación para adaptarse a la realidad del subdesarrollo es, en cierta medida, el fin de la esperanza y pensar que siempre nos quedaremos en el subdesarrollo» ${ }^{29}$.

En cualquier caso, el subdesarrollo cultural al que aludía Traba no suponía avalar la, a su juicio, vergonzosa dependencia de la que hacían gala muchos creadores latinoamericanos, una dependencia criticada ferozmente por la autora argentina, como se puso de manifiesto en el pequeño debate en torno a la figura de Borges, destacado por Ashton y Bayón desde planteamientos muy distintos y siempre por extensión dirigidos también al mundo del arte. Así, en la primera sesión del simposio Dore Ashton había expuesto con claridad cuáles eran los peligros de una visión nacionalista del arte latinoamericano, y lo hizo apoyándose en la lectura de un texto de Borges titulado «El escritor argentino y la tradición». Ashton creía que la postura de Borges que se deducía de ese texto debía verse como una prevención frente a lo que sería una visión puramente nacionalista de la creación artística:

26. M. Traba, Primera sesión...”, op. cit., 38.

27. M. Traba, Primera sesión...”, op. cit., 38.

28. M. Traba, Primera sesión..., op. cit., 40.

29. R. Eder de Blejer, “Segunda sesión..., op. cit., 82. 
«Él habló de nacionalistas "que quieren limitar el ejercicio poético de esa mente a unos pobres temas locales, como si los argentinos sólo pudiéramos hablar de orillas y estancias y no del universo"». La cita de Borges se veía además reforzada por otras declaraciones posteriores del autor argentino, en las que este «denunciaba los peligros inherentes a lo que él llama "el simulacro de la conciencia latinoamericana" ${ }^{30}$ Por su parte, Damián Bayón había acudido al ejemplo de Borges para subrayar la mayoría de edad de la cultura latinoamericana, toda vez que este autor aparecía citado como referencia por autores tan sofisticados como el filósofo francés Foucault. Para Traba, sus preferencias por los textos de Borges pasaban por la mirada que este dirigía a lo local, «lo argentino, lo bonaerense, lo porteño» por encima de otras obras suyas como el cuento La biblioteca de Babel. La referencia de Bayón a Foucault y la cita que hace de Borges lo que ponía de manifiesto, según su criterio, era la necesidad enfermiza que los intelectuales latinoamericanos tenían de buscar una homologación con el mundo occidental. Hay, por tanto «una cosa neurótica de asunción de la dependencia cuando estamos muy felices de que nos inviten a un simposio en Estados Unidos o en Francia, porque, ¡Dios mío!, se dieron cuenta de que existimos» ${ }^{31}$.

No puede decirse, en todo caso, que las disertaciones de Damián Bayón y Marta Traba durante el encuentro de Austin acabaran siempre con discrepancias entre ellos. De hecho, Bayón veía también en la originalidad de los planteamientos de artistas como Torres-García, Tamayo, Matta o los cinéticos venezolanos una prueba evidente de la madurez de la creación latinoamericana, más allá de lo que sería un seguimiento acrítico de los lenguajes internacionales y muy en línea con el fenómeno del mestizaje, algo que consideraba consustancial a la cultura latinoamericana. Cuando se trataba, sin embargo, de atender a las tendencias últimas, tan vituperadas por Traba, Bayón se volvía cauto y aunque consideraba que tendencias como el arte conceptual o el arte ecológico no eran propiamente «arte avanzado», si valoraba su dimensión experimental, a la vez que subrayaba también la mirada bien distinta que tenían sobre este tema los críticos brasileños presentes, Aracy Amaral y, sobre todo, Frederico Morais.

Una de las aportaciones más interesantes de los participantes en el evento de Austin en torno a la cuestión de la identidad fue sin duda la del crítico mexicano Jorge Alberto Manrique, quien entendía la naturaleza peculiar de la cultura latinoamericana inserta en el ámbito de una «ambigüedad consustancial», pues esta pertenecía y no pertenecía al mismo tiempo al modelo occidental. En definitiva, en el arte latinoamericano pueden rastrearse modelos de raíz occidental o autóctonos, frecuentemente combinados entre sí, con mayor o menor predominancia de uno o de otro. "Cada vez que queremos probar -escribía el crítico- lo occidentales que somos, exactamente iguales al modelo que se nos propone, descubrimos al mismo tiempo que no somos occidentales» ${ }^{32}$. En cualquier caso, había que añadir a todo ello algo que hacía distintivo al arte latinoamericano frente a los modelos extranjeros, y esto era la fuerza con la que revelaba el peso de las circunstancias culturales en el espacio propio de su desarrollo, pues «no es lo mismo hacer un arte geométrico difícilmente distinguible del que

30. D. Ashton, “Primera sesión...”, op. cit., 29.

31. M. Traba, "Primera sesión...”, op. cit., 50.

32. J. A. Manrique, “Segunda sesión..., op. cit., 73. 
se produce en un París, un Nueva York o Londres y no es lo mismo buscar en él un sentido local: el geometrismo que se haga en un país latinoamericano tiene por sólo ese hecho, un sentido diverso, está dando una explicación de la realidad latinoamericana $»^{33}$.

En las discusiones mantenidas en los debates de Austin, los críticos brasileños asistentes, Aracy Amaral y Frederico Morais, se expresaron con voz propia ${ }^{34}$, mostrando así que procedían de un ámbito cultural que había vivido la modernidad con dinámicas no exactamente coincidentes con las manifestadas en otras áreas latinoamericanas. Qué duda cabe que la postura de Amaral, una crítica cuya trayectoria se había iniciado en los sesenta, pero con creciente protagonismo en las décadas posteriores ${ }^{35}$, se manifestaba en clave de confrontación. En este sentido, puede considerarse sus planteamientos críticos como los más cercanos a los de Marta Traba. Para la brasileña Latinoamérica era un territorio ocupado por modelos foráneos, occidentales que entraban en contradicción con la esencia de la cultura local, que era sobre todo popular:

...nosotros tenemos que volver - en un debate sobre el arte latinoamericano- sobre el problema de lo erudito, de lo popular, porque en realidad lo popular es nuestra realidad y lo erudito son los modelos (...) Los modelos que se presentan como comportamiento son todos europeos o anglosajones, al paso que la realidad es mestiza. Es por eso que también no puedo aceptar esa declaración de Bayón, de ayer, cuando se refirió a la neurosis de la dependencia. Claro que, si los modelos son de afuera, nosotros tenemos el problema de esa ambigüedad, esa rebelión contra un modelo que sabemos que no corresponde a nuestra realidad ${ }^{36}$.

Para Morais, sin embargo, la especificidad del arte brasileño radicaba en su clara preferencia por lo constructivo, algo que se había puesto de manifiesto en la década de los cincuenta y cuya persistencia se constataba posteriormente. Y si bien se podía pensar en el arte constructivo como algo propio de Brasil, otros países latinoamericanos, como Colombia o México no eran ajenos a esta orientación plástica. Lo interesante del planteamiento del crítico brasileño radicaba en que este se defendía también como propuesta de largo recorrido. Apoyándose en unas declaraciones del escultor constructivista mexicano Manuel Felguérez, que alentaba a buscar la especificidad de lo latinoamericano en propuestas de futuro y no en la revisión de épocas pasadas, Morais apuntaba en la misma línea al afirmar que «lo específico latinoamericano no debe ser buscado en su aspecto referencial (...) Acredito que el carácter propio de nuestro arte estaría en la búsqueda de esa voluntad general de construcción» ${ }^{37}$.

33. Jorge Alberto Manrique, “Segunda sesión...”, op. cit., 69.

34. Ambos, además, dejaron referencia escrita sobre los debates críticos del simposio. Vid. A. Amaral, "Simpósio de Austin", en Arte e meio artístico: entre a feijoada e o x-burger, São Paulo, 1982, 222-234; F. Morais, Las artes plásticas en América Latina: del trance a lo transitorio, La Habana, 1990.

35. Será muy revelador el papel desempeñado por ella en torno a la celebración de la I Bienal Latinoamericana en São Paulo (1978).

36. A. Amaral, "Segunda sesión...”, op. cit., 72-73.

37. F. Morais, “Cuarta sesión (29 de octubre)”, op. cit., 128. 


\section{Visiones de la crítica}

Aunque en menor escala si lo comparamos con el tema de la identidad, también hubo en Austin espacio para el debate en torno a la crítica de arte como disciplina, algo que se había visto suscitado en gran medida por las propuestas de los organizadores. De la crítica se valora su eficacia, su función diversa, su propia naturaleza como actividad de creación, las relaciones entre crítico y artista, y también su diversidad tipológica. Como ocurría con el tema de la identidad, la aportación de los artistas en el debate fue algo no desdeñable.

En la lectura de su ponencia, Juan Acha fue muy taxativo con respecto a los valores de la crítica latinoamericana, que él consideraba que era de mala calidad porque carecía de fundamentos teóricos sólidos y no estaba abastecida por una historia del arte bien potente ${ }^{38}$. Para el peruano, las dificultades que entrañaba la mala relación existente entre crítica y artista podrían lastrar el desarrollo del arte latinoamericano, a la vez que «seguirán haciendo de las suyas el imperialismo cultural y los dirigismos locales $\star^{39}$. Por el contrario, al aportar sus reflexiones sobe la crítica, el pintor Rufino Tamayo disentía frontalmente de lo expuesto por Acha, pues si bien éste buscaba la colaboración entre crítica y arte como el ideal para el progreso de las artes, el artista mexicano entendía que la crítica estaba pensada para el público, como una guía para poder entender la obra plástica, y no para el creador. Otra cosa sería la autorreflexión del artista sobre su obra, lo que podría llamarse autocrítica, algo que consideraba realmente importante.

Parte del debate sobre este tema se centró en la diversidad de la crítica en relación con las funciones desempeñadas por esta. Es muy aleccionador, a este respecto, el análisis que se puede hacer sobre las intervenciones del escultor Manuel Felguérez y del crítico Jorge Alberto Manrique, quienes trataron de matizar las argumentaciones de Tamayo sobre este tema. Según el crítico mexicano, lo que predominaba en los ambientes artísticos latinoamericanos no era tanto una crítica «actuante», que recogiera directamente las novedades artísticas, propia del mundo periodístico, como una «crítica-testimonio», más elaborada teóricamente, pero más distante con respecto a los procesos artísticos inmediatos. Si bien esto podría interpretarse en un sentido positivo, porque «libera a la crítica en Latinoamérica de los compromisos e incluso de los cohechos que son más comunes en otros lados» ${ }^{40}$, mostraba también una carencia en el sentido de que confirmaba unas limitaciones en la difusión de la información artística que afectaba finalmente a los propios creadores. Desde luego, Manrique no negaba la existencia de una crítica periodística, pero la consideraba de baja calidad. Había también en sus planteamientos espacio para lanzar una alerta sobre las consecuencias negativas que podía suponer para la crítica anteponer las certezas ideológicas al estudio concreto de la obra de arte, un defecto que veía no solamente en la crítica latinoamericana sino en general. Por su parte, Felguérez se hizo eco de las opiniones de Tamayo respecto a la importancia para el

38. Acha volvió a insistir con parecidos argumentos en la reunión de Caracas. Vid. J. Acha, "Primer encuentro iberoamericano de críticos y artistas”, El Universal, 30 de julio de 1978.

39. J. Acha, “Cuarta sesión..., op. cit., 120.

40. J. A. Manrique, “Segunda sesión..., op. cit., 74. 
artista de la autocrítica para entender la evolución del proceso creador, pero el papel de la crítica como intérprete del lenguaje artístico, cómo traductor de un lenguaje plástico concreto, «si bien no le interesa al artista mismo, le es vital para sus existencias, puesto que, si no hay el traductor, el fenómeno de aceptación de ciertos valores estéticos se alarga, toma tiempo» ${ }^{41}$. Distinguía el escultor mexicano entre dos tipos de crítica: la calificada como «testimonio», siguiendo así las palabras de Manrique, y la propiamente periodística, que él relacionaba con los poetas y literatos en general, y que "por comprender los fenómenos lingüísticos, son los que normalmente han sabido mejor captar una obra de arte» ${ }^{42}$. Al final de su intervención, Felguérez se aventuró a señalar la existencia de una tercera crítica que él veía plasmada en la actividad cultura del Estado, una crítica en sentido muy negativo, pues asociada a valores que defienden las razones de poder, podía considerarse también como una censura.

Cabe, finalmente, dirigir la mirada hacia la contribución de Morais sobre este tema, seguramente la más interesante, en la medida en que recogía la originalidad de los planteamientos críticos de Brasil y, además, una sensibilidad hacia el fenómeno artístico contemporáneo mucho menos reactiva que la mostrada por Traba. Le interesaba al crítico brasileño exponer un diagnóstico que él tomaba (sin mencionarlo) de Mario Pedrosa: en la década de los sesenta el arte contemporáneo había entrado en una etapa nueva, postmoderna. La superación de la modernidad, entre otros aspectos, se caracterizaba por «una mudanza continua de posiciones. En este sentido, el crítico puede ser un artista, como el artista puede ser también un crítico ${ }^{43}$. El ejemplo del arte conceptual, tan vituperado por Traba, era muy elocuente, sobre todo por su naturaleza tautológica, esto es por lo que suponía de reflexión del artista sobre su propia creación. Morais, además, rechazaba el juicio negativo de Octavio Paz, que veía una ausencia de pensamiento crítico en América Latina. Al menos en Brasil, se había manifestado una teorización de un pensamiento crítico en torno al movimiento concreto, que, si bien bebió inicialmente de las fuentes europeas, había mutado en este país latinoamericano mediante "un proceso de nacionalización», hasta adquirir «unas características más orgánicas como en el caso del "tropicalismo"» ${ }^{44}$.

\section{Arte y política: la herencia revolucionaria mexicana y el caso cubano}

Dos paradigmas salen a relucir en torno a este tema: el de la revolución mexicana, analizado en perspectiva histórica, y el de la revolución cubana, presente como fenómeno político actuante del que se quiere sacar conclusiones, toda vez que, fallida la tentativa socialista chilena, resultaba el único ejemplo contundente de revolución política en el espacio latinoamericano. No estaba previsto en el programa de las discusiones de Austin debatir sobre el caso cubano,

41. M. Felguérez, "Segunda sesión...”, op. cit., 77.

42. M. Felguérez, "Segunda sesión...”, op. cit., 78.

43. F. Morais, “Cuarta sesión..., op. cit., 116.

44. F. Morais, “Cuarta sesión...”, op. cit., 116. 
pero el tema salió de manera reiterada, sobre todo cuando los contenidos de las conversaciones se enfocaban hacia la relación entre arte y revolución.

Al tratar de un tema tan concreto como era el de la relación entre arte y política, los intelectuales latinoamericanos de la época mostraban una postura muy alejada de los pronunciamientos puramente teóricos o académicos y más cercana a vivencias que en mayor o menor medida afloraban en las discusiones del simposio. Así Jorge Alberto Manrique sacó en su momento a colación la represión estudiantil por parte del gobierno mexicano en 1968, que, paradójicamente, polarizó la protesta firme de artistas alejados de la vieja escuela mexicana, mientras que los vinculados a esta, «tradicionalmente de izquierda, no abrían la boca» ${ }^{45}$. Precisamente, debido a la experiencia mexicana había una prevención que no dejó de salir en los comentarios de algunos de los participantes en el evento que estudiamos, como sucede con el pintor Tamayo. Apuntaba este artista cómo en México se había conseguido plasmar un arte «hecho por revolucionarios, pero no revolucionario», ya que su utilidad fue meramente propagandística al servicio del Estado, una idea, por otra parte, que sostendrá también Octavio Paz en algunos de sus escritos. Para Tamayo, la pintura revolucionaria era «la que abre nuevos caminos, no la que utiliza temas sociales o políticos para llamarse revolucionaria» ${ }^{46}$.

Pero ¿cabía hablar en el mismo sentido con respecto a la experiencia cubana? No parece, a juzgar por las opiniones que en ese foro se emitieron, aunque en algunas de ellas se muestra un cierto desconcierto ante la expectativa de un arte nuevo en un país donde se ha producido una trasformación política radical y los resultados que son contrastables. Este desconcierto está bien representado en las opiniones de Fernando de Szyszlo, que ve con cierto asombro cómo en la isla se pueden encontrar retratos de José Martí al modo Warhol, pero, sin embargo, no encuentra un verdadero arte revolucionario. Por su parte, Rita Eder de Blejer valora el nuevo arte cubano como ejemplo de arte de resistencia, tomando así prestado el concepto defendido por Traba. Para la historiadora mexicana, que habla más bien en clave de futuro, estábamos asistiendo a la irrupción de un nuevo arte revolucionario, que «no consiste en dictar o enfatizar cómo deben ser las formas, sino en plantear un nuevo concepto de la estética, no sólo con énfasis en el objeto en sí, sino en el hecho de proponer como una interacción vital entre arte, artista y pueblo» ${ }^{47}$.

El mismo Bayón revela sobre este tema también su sorpresa cuando vio en Cuba cómo las tendencias occidentales como el pop art o el op art estaban presentes entre los creadores de la isla. Pero como explicará también Traba sobre este asunto, la política artística cubana iba dirigida sobre todo a potenciar las artes reproductivas, los afiches, pósteres y vallas, donde se aprecian obras de destacable calidad. Había, además, otro aspecto, y es que «el gobierno cubano tuvo la excelente idea de no limitar (hubo un momento de flotación, una tentación de realismo socialista apenas pasado el triunfo de la revolución, después se recuperaron y dejaron entera libertad a los artistas) ${ }^{48}$ La conclusión para el historiador y crítico argentino

45. J. A. Manrique, “Cuarta sesión..., op. cit., 146.

46. R. Tamayo, “Segunda sesión..., op. cit., 93.

47. R. Eder de Blejer, “Segunda sesión..., op. cit., 82.

48. D. Bayón, “Cuarta sesión...”, op. cit., 131. 
no ofrecía dudas, pues cabía hablar de una revolución artística en marcha que se basa en el ideal de educar al pueblos sin renunciar por ello a los lenguajes artísticos contemporáneos, incluso a aquellos que, como el cinetismo, no aportaban un componente figurativo, algo que el éxito reciente del artista argentino Le Parc en La Habana ponía de manifiesto.

También sobre este tema Marta Traba expuso un argumentario que podemos considerar en sintonía con los planteamientos de Bayón, aunque con algunos matices interesantes. Lo importante para ella no era tanto los cambios perceptibles en las artes de tradición burguesa como la pintura y la escultura, sino la preocupación mostrada por el gobierno cubano por ampliar las fronteras del público interesado por el arte, a la vez que se destruía el funcionamiento habitual del mercado artístico en los países capitalistas. De manera que cabía hablar de un nuevo panorama caracterizado por una apertura a las formas de expresión con mayor incidencia colectiva. Esto es:

...la importancia que se le dio al cortometraje, el saneamiento del cine (buscar a través de las imágenes del cine, del nuevo cine, una clara educación visual, no me refiero solamente a una tonta educación de niveles pedagógicos ínfimos sino a una clara educación visual), la importancia que se le dio a la gráfica, la revaluación de la gráfica, teniendo en cuenta buenos antecedentes. Todas estas cosas, me parece a mí que son las positivas, las dignas de señalarse dentro del proceso cubano... ${ }^{49}$

A ojos de Traba, el régimen cubano impulsaba una cierta autonomía en relación con el modelo comunista oficial de la Unión Soviética, de modo que podía decirse que en la isla había un respeto a la libertad de expresión creativa que contrastaba con la esclerosis de los programas oficiales de aquel país, dicho esto como la constatación de una realidad del momento y no como algo inmutable cara al futuro.

\section{El escenario norteamericano y los protagonistas anglosajones}

Como ya adelantamos, la celebración del simposio de arte y literatura en la ciudad de Austin (Texas), fue un hecho destacable no solamente por lo que implicaba de espacio cultural específico, sino también por la significativa contribución de los críticos e historiadores estadounidenses ya mencionados ${ }^{50}$. Los norteamericanos no solamente cedieron los locales para la celebración del simposio y la muestra organizada por la revista Plural, sino que participaron activamente en los debates suscitados por este encuentro internacional. Además, en la Universidad de Texas colaboraban como profesores en esos años Damián Bayón y el mismo Octavio Paz. Por otra parte, no debe olvidarse que en los Estados Unidos se había producido, desde la década de los sesenta, una reactivación del interés por el arte latinoamericano ${ }^{51}$.

49. M.Traba, “Cuarta sesión..., op. cit., 132.

50. De hecho, el inglés estuvo presente en las sesiones del simposio junto al español y el portugués.

51. Un interés que Edward J. Sullivan quiso relacionar directamente con las iniciativas culturales impulsadas por los gobiernos norteamericanos en el contexto de la Guerra Fría. Vid. E. J. Sullivan, El arte latinoame- 
Algunos de los artistas participantes en las reuniones de Austin, tal es el caso de los mexicanos Tamayo, Manuel Felguérez y José Luis Cuevas; también el peruano Fernando de Szyszlo, habían pasado estancias en los Estados Unidos. De modo que cabe hablar de un innegable entrecruzamiento de vivencias con la cultura norteamericana por parte de los creadores latinoamericanos que cuesta entender como algo carente de cualquier repercusión, aunque esta fuera explicada en última instancia como algo negativo, si juzgamos las opiniones de José Luis Cuevas en una de sus intervenciones en los debates. Conviene detenernos, aunque sea brevemente, en este episodio porque ilustra de manera fehaciente hasta qué punto la presencia de los artistas latinoamericanos en los Estados Unidos propiciaba una diversidad de posturas. Para Cuevas, la identidad de un arte latinoamericano no tenía duda alguna, y esta certeza se había visto reforzada por su experiencia tanto en Europa como en los Estados Unidos, donde pudo ver la actitud de los artistas latinoamericanos «un poco de mendigos en busca de unas líneas elogiosas que aparecieran en Art News o en el New York Times» ${ }^{52}$. Según el pintor mexicano, sin embargo, su presencia en los Estados Unidos debía entenderse siempre desde la afirmación de su diferencia con respecto al arte dominante en ese contexto del norte. Pese a que reconocía algunas opiniones favorables hacia su pintura de algunos críticos norteamericanos, como sucedía con Dore Ashton, Cuevas estaba muy interesado en señalar que él «no llegaba a Nueva York con el afán de copiar lo que allí se estaba haciendo sino con la intención de aportar una visión nueva», muy lejos del «arte colonial» ${ }^{53}$, que, según él, hacían muchos artistas latinoamericanos residentes en ese país. Fernando de Szyszlo, otro artista participante en el simposio, con experiencia vivida también en los Estados Unidos, expone un análisis más distanciado sobre este tema, a la vez que más optimista, incidiendo en la constatación de que la situación de los artistas latinoamericanos estaba cambiando. Esto era así no solamente por el desconcierto del arte occidental y la esterilidad de su crítica frente al fenómeno de la crisis de la pintura, sino también por el desarrollo de unas condiciones favorables en el espacio urbano latinoamericano, donde se había generado un coleccionismo nuevo, la aparición de galerías y museos que sentaban las bases de una situación inédita que permitía la reubicación internacional de la creación latinoamericana. En definitiva,

Creo que, en los mejores casos, el arte de América Latina ha cesado, no digo ya de soñar, de interesarse fundamentalmente en lo que fue considerado hace algunos años como su única puerta de salida: que directores ideales de museos o críticos de Europa o los Estados Unidos lo descubrieran; y ha superado al mismo tiempo sus dos más graves tentaciones. La tentación de

ricano en el siglo XX, Madrid1996, 12. Dos colectivas importantes en estos años subrayan esta atención por lo latinoamericano: por un lado, la titulada «Art of Latin America since Independence», celebrada en el Yale University Art Gallery en 1969 y organizada por Terence Grieder y Stanton L. Catlin, ambos presentes en el simposio de Austin, por cierto; por otro, «The Emergent Decade: Latin American Painters and Painting in the 1960's», que fue responsabilidad de Thomas Messer. A ello se unía la circunstancia de que las primeras contribuciones a una historia del arte latinoamericano contemporáneo, la del chileno Leopoldo Castedo y la del norteamericano Gilbert Chase, están escritas en inglés.

52. J.L. Cuevas, “Primera sesión..., op. cit., 29.

53. J.L. Cuevas, “Primera sesión..., op. cit., 29. 
remedar para ser aprobado y la de perderse en un folklorismo banal que finalmente buscaba por otro camino, pero con igual ingenuidad, la misma aprobación ${ }^{54}$

Pero ¿qué alcance tuvieron las intervenciones de los críticos e historiadores norteamericanos en los debates del simposio? Al referirse años después al encuentro de Austin, la historiadora Andrea Giunta quiso subrayar la importancia que tuvo la postura de los críticos latinoamericanos de confrontación frente «a la política cultural de los Estados Unidos», debatiendo, además, «hasta qué punto los artistas y los críticos debían apartarse de su influencia, vinculándose al contexto latinoamericano ${ }^{55}$. Una crítica presente en el simposio, la brasileña Aracy Amaral juzgó la presencia de los norteamericanos más bien como de meros observadores «da efervescencia de problemática de um continente em expansão» ${ }^{56}$; esto es, el simposio de Austin se trató sobre todo de un encuentro latinoamericano. Sin embargo, no está tan clara la postura supuestamente distante de los participantes norteamericanos en las sesiones de este evento, a juzgar por la lectura de los contenidos de los debates. Al contrario, cabe pensar que sus opiniones revelaban una implicación clara en la realidad artística latinoamericana, lo cual suscitó en más de una ocasión la réplica de los participantes latinoamericanos en el sentido que apunta Giunta, aunque las intervenciones de unos y de otros están llenas de matices que impiden llegar a conclusiones demasiado tajantes. Desde luego, no es difícil entender que algunas diferencias en las posturas tenían que ver con tradiciones culturales y condicionantes socioeconómico claramente diferenciados.

Entre los norteamericanos intervinientes en Austin, tanto Stanton Catlin como Grieder tenían en esos momentos un acreditado conocimiento del mundo artístico latinoamericano, tanto del precolombino como el de periodos posteriores. También era el caso de Bárbara Duncan, que había vivido en Perú durante ocho años y se había doctorado en arte colonial peruano y luego en la obra de Torres García. A esas alturas, Duncan había organizado en Austin dos exposiciones sobre artistas latinoamericanos, dedicadas a Torres García y Gunther Gerzso sucesivamente. Posteriormente, el museo de Austin (Blanton Museum) sería el depositario de una importante donación de obras latinoamericanas procedente de su colección. Más discreto era en ese momento el perfil latinoamericanista de Jacqueline Barnitz, que tendrá posteriormente una definición muy destacable. En todo caso, siendo Dore Ashton la más alejada de ese mundo, fue seguramente la que más se implicó en las controversias generadas por las lecturas de las ponencias de distintos críticos latinoamericanos, especialmente por lo que se refiere al tema de la identidad, pero también a la polémica sobre arte y política. Ya hemos visto cuál era su posición sobre el tema de la identidad a propósito de un texto de Borges y la respuesta crítica de Marta Traba a sus argumentos. En la segunda sesión del simposio, la crítica norteamericana tuvo la oportunidad de insistir en este asunto, pero extendiéndolo al ámbito del arte contemporáneo en su conjunto, incluyendo, por tanto, áreas

54. Fernando de Szyszlo, "Primera sesión..., op. cit., 37.

55. Andrea Giunta, "América Latina en disputa. Apunte para una historiografía del arte Latinoamericano", en: Los estudios de arte desde América Latina, Oaxaca, 1996.

56. Aracy Amaral, “Do simposio de Austin”, en op. cit., 222. 
culturales distintas de la latinoamericana. De lo que se trataba era de confirmar que la tensión dialéctica entre lo particular y lo universal había sido algo intrínseco a la modernidad, no exclusivo de América Latina, como se constaba en espacios culturales tan distintos como la Escuela de París o la Rusia revolucionaria de Malevich y Tatlin. Esto es,

En todo lo largo del siglo XX ha habido una tensión entre los impulsos nacionales (con todas las ambigüedades de bueno y malo que conlleva); y el fundamentalmente carácter internacional de la cultura occidental del periodo moderno. Los artistas latinoamericanos, como todos los otros artistas, como los artistas de mi propia ciudad, Nueva York, están sujetos a los conflictos inherentes a la moderna cultura occidental ${ }^{57}$

Planteados de esta forma su punto de vista, la autora norteamericana remarcaba un posicionamiento alternativo a las grandes líneas de debate sobre la identidad defendidas por críticos latinoamericanos como Juan Acha o Marta Traba, o artistas como Cuevas. Por otra parte, Ashton también abordó el tema del arte de crítica social y la novedad de su planteamiento en el contexto latinoamericano, condenado en algunos casos a «una situación política extrema», como se veía en el ejemplo del grupo C.A.Y.C. de Buenos Aires. Se trataba esta de una experiencia cuyos recursos le producían una clara desconfianza, pues representaban «una desdichada capitulación frente a la nueva e impresionante terminología francesa del estructuralismo, epistemología y los otros ismos que tanto hemos oído en esta conferencia, me parecen el resultado de una situación extremadamente incómoda. El énfasis crítico en el criticismo se abandona a un tipo de comunicación que puede ser fatal para el artista ${ }^{58}$. También se refirió la autora norteamericana en sus intervenciones al arte de los países llamados socialistas, un tema que había suscitado Marta Traba a propósito de Cuba, y que ella quiso extender a toda el área socialista en su conjunto. En su opinión, que el término "socialista" fuera deseable, no podía ocultar una realidad en el arte de estos países que basculaba entre las expresiones del mundo del cartel y el cine, vehículos de un "programa educacional", y aquellas otras que eran propias de una "comunidad disidente e insatisfecha de artistas y literatos, que, estando totalmente embarcados en la posición socialista, no pueden someterse al empleo utilitario que del arte hace a veces el marxismo. Y estas tragedias personales de esos artistas, me parece a mí que nos están señalando algo» ${ }^{59}$. Se trataba, por tanto, de una opinión que incidía en la libertad de creación y que cuestionaba la viabilidad de esta bajo un régimen político con perfiles ideológicos tan definidos. Para Ashton, debía esclarecerse hasta qué punto la situación en Cuba era diferente o no. En realidad, a lo que apuntaba toda esta polémica era a la relación entre arte y poder, una relación que, como señalaba la crítica, no hace distingos entre izquierda y derecha. Siguiendo en estos aspectos a Plejanov, se trataba de ver quién iba a responsabilizarse de los programas de los artistas, con independencia de la renovación de los lenguajes.

57. Dore Ashton, “Segunda sesión..., op. cit., 71.

58. Dore Ashton, “Segunda sesión..., op. cit., 72.

59. D. Ashton, “Cuarta sesión...”, op. cit., 133. 
También Jacqueline Barnitz se adentró en algunas de sus intervenciones en el polémico tema de la identidad ${ }^{60}$ y la originalidad de la obra de arte latinoamericana. Subrayaba en todo caso esta historiadora cómo para ella era evidente no sólo la singularidad de muchos artistas del subcontinente; también el carácter anticipatorio de sus obras, tal como se podía ver en la producción del cinetista venezolano Otero. Lo mismo podía decirse de su compatriota Soto, al que conoció en París. De modo que «cuando Vasarely empezó a trabajar o cuando Agam apareció, se puede decir que los venezolanos lo estaban haciendo. Y me parece que es hora de que reconozcamos hasta qué punto debemos tantas novedades a los artistas latinoamericanos ${ }^{61}$. A Barnitz, sin embargo, le resultaba difícil de aceptar el concepto de resistencia en los términos aireados por Marta Traba. Y esto era así porque las influencias foráneas llegan continuamente y es difícil evitarlas. En definitiva, «no creo que se pueda hablar, digamos, en términos de "imperialismo cultural" porque los artistas latinoamericanos buscan sus fuentes donde quieren».62 Según su opinión, un buen ejemplo sería el del colombiano Santiago Cárdenas, que, si bien había trabajado en los Estados Unidos durante varios años, había desarrollado un lenguaje propio que en nada recordaba a lo hecho por los artistas norteamericanos. Más adelante, durante el transcurso de los debates, la historiadora norteamericana quiso dar su opinión sobre las diferencias que ella encontraba entre la crítica latinoamericana y la estadounidense, refiriéndose sobre todo a Nueva York. Para esclarecer las diferencias entre ambas, Barnitz tomó como modelo idóneo la crítica "anarquista" de Marta Traba, "porque en vez de intentar una metodología que le impida moverse, que hace del arte "otra cosa", ella en realidad defiende y se hace la campeona de ciertos artistas a quienes anima a trabajar libremente, de modo que puedan lograr estímulo local y no tener que buscarlo en sitios como París o Nueva York» ${ }^{63}$. Por el contrario, estaba el ejemplo neoyorkino, donde el seguimiento estricto de las metodologías llevaba a los críticos a desinteresarse por los temas y donde se imponía determinadas orientaciones no bien asimiladas. Era el caso de la crítica de matiz político que se había impuesto tras el 68 y el golpe militar en Chile. Lo cierto era que «muchos de los críticos que escriben así no tienen la más remota idea de lo que están escribiendo. Sólo saben que es algo que "está en el aire" y forman así parte todavía de un establishment, lo que hace la situación difícil para ciertos artistas que no están trabajando en el sentido que se espera de ellos en ese momento» ${ }^{64}$.

Al igual que Barnitz, Barbara Duncan no albergaba dudas respecto a la naturaleza singular del arte latinoamericano en el contexto mundial, contexto que ella califica en varias ocasiones de global. Para la norteamericana, la certeza de este nuevo escenario se planteaba desde cierta prevención, precisamente por lo que podía suponer de amenaza

60. Previamente Jacqueline Barnitz había profundizado sobre esta cuestión en un artículo titulado "The Question of Latin American Art: Does it Exist?", Arts Magazine, 47,3, 1966-67, 53-55.

61. J. Barnitz, “Primera sesión...”, op. cit., 52.

62. J. Barnitz, “Primera sesión..., op. cit., 53.

63. J. Barnitz, “Cuarta sesión...”, op. cit., 122.

64. J. Barnitz, “Cuarta sesión...”, op. cit., 122. 
para esa identidad: «Hablando siempre de esos artistas, siento que no han perdido el sentir de su identidad, aunque todos enfrentemos el peligro de la "cultura global", como ha dicho repetidamente Marta Traba. Y estoy muy de acuerdo con ella, en el sentido de que el mundo perdería muchos elementos de su personalidad si ello ocurriera» ${ }^{65}$. Dejado bien sentada esta certeza y destacando el fenómeno de la movilidad creciente en el mundo de los transportes que permitía una mayor aproximación de los artistas a otras áreas culturales, la norteamericana incidía en una circunstancia que en este simposio fue aireada en varias ocasiones precisamente por los participantes de habla anglosajona: el papel de la economía y el patronazgo en el mundo del arte. Se trataba de un asunto de tipo sociológico y económico que diferenciaba claramente el mundo norteamericano del latinoamericano. Por experiencia vivida en Latinoamérica, a Duncan le llamaba la atención «la falta de comprensión del papel saludable de la economía dentro de esos países. La vida cultural en el sector artístico es generalmente la primera en sufrir en periodos de depresión ${ }^{66}$. Semejantes afirmaciones fueron recogidas en el debate por otros participantes, especialmente por el crítico mexicano Jorge Alberto Manrique, que quiso complementar las aseveraciones de Duncan con una llamada al problema de la falta de una educación artística incentivadora y el desinterés de las clases dirigentes latinoamericanas por estos temas:

Ciertamente, la riqueza acumulada en una ciudad como México o aun como Caracas, es muy inferior a la acumulada en ciudades de los Estados Unidos; pero no es solo eso, sino que la gente que tiene dinero no compra, la gente que tiene dinero no hace donaciones, la gente que tiene dinero no ayuda a museos, y no es sólo ese problema, sino que las gentes en los puestos de mando y gobierno tampoco se interesan sino muy limitadamente por estos aspectos ${ }^{67}$.

También la mexicana Rita Eder quiso dar réplica a la argumentación de Duncan, pero desde unos planteamientos claramente críticos, toda vez que juzgaba que el análisis de la norteamericana confirmaba la tradicional relación asimétrica existente entre Latinoamérica y los Estados Unidos, esto es, una relación marcada por la dependencia: «Creo que desde luego la señora Duncan, con toda buena fe y educación nos dio todo un testimonio de que los problemas de los años treinta siguen vigentes, expresando hacia Latinoamérica la eterna actitud del paternalismo» ${ }^{68}$

Se volvió a tocar el tema del patronazgo a propósito de la intervención del historiador Terence Grieder, quien comenzó su disertación con un reconocimiento explícito a la enorme influencia que el arte latinoamericano, a través de la figura de los muralistas mexicanos, había tenido en los Estados Unidos durante los años treinta. Como había subrayado Duncan en una de sus declaraciones, corroborado por Jorge Alberto Manrique, el patronazgo artístico en América Latina podía considerarse como un fenómeno de poca vitalidad, algo que esta-

65. B. Duncan, “Tercera sesión (29 de octubre), op. cit., 109.

66. . B. Duncan, “Tercera sesión (29 de octubre), op. cit., 100.

67. J. A. Manrique, “Tercera sesión..., op. cit., 105.

68. R Eder de Blejer, “Tercera sesión...”, op. cit., 114. 
ba motivado no solamente por la falta de interés, también por las dificultades económicas existentes. Por el contrario, en los Estados Unidos el apoyo estadounidense al arte latinoamericano era un fenómeno de tanta vitalidad que había sustanciado «un diálogo entre latinoamericanos creadores y coleccionistas norteamericanos», lo que podía entenderse como una distorsión de lo que debía ser una auténtica relación entre arte y público. Grieder, en todo caso, no dejaba de ver el apoyo económico norteamericano como algo positivo y en un plan algo desafiante exponía la situación de forma disyuntiva: «Hay un tremendo aporte norteamericano en el diálogo y no se trata de imperialismo. Si los artistas latinoamericanos no están dispuestos a aceptar esta situación...se tienen que quedar en casa y vender localmente ${ }^{69}$.

Por su parte, la breve aportación de Stanton L. Catlin al simposio estuvo orientada a alertar, desde sus conocimientos de historiador del arte, del peligro que amenazaba al patrimonio artístico latinoamericano, cuya dispersión en el tiempo y el espacio suponía además una dificultad añadida. Se trataba, por tanto, de mejorar el conocimiento de ese amplio mundo artístico: «...creo que es terriblemente importante empezar a catalogar las obras de arte sobrevivientes que representan una inapreciable herencia para el continente latinoamericano y el conjunto de su arte» ${ }^{70}$.

\section{Epílogo: una carta de Octavio Paz}

Pocos meses después de la clausura del simposio de Austin, escribió Octavio Paz una carta a su organizador, Damián Bayón, carta en la que se hacía eco de los debates habidos, tomando como referencia el artículo que el crítico argentino había escrito sobre esta reunión y sus resultados $^{71}$. Si sacamos a colación ahora este documento es porque, en gran medida, ayuda a profundizar en una línea de pensamiento en torno al arte contemporáneo de la que tuvimos ya una primera impresión en el texto que servía para inaugurar este evento, como vimos.

Algunas afirmaciones de Paz que se pueden leer aquí resultan contundentes por la claridad y la naturaleza indubitada de su exposición, como cuando se refiere a las declaraciones de algunos críticos que apuntan a un indigenismo radical. «No puedo resignarme todavía -escribía el poeta- a oír esas tonterías sobre "la cultura latinoamericana ocupada desde la época de los españoles y portugueses" $\gg^{72}$. A Paz le resultaba elogiosa la postura de críticos e intelectuales latinoamericanos como Bayón, que habían sido capaces de en-

69. T. Grieder, “Cuarta sesión...”, op. cit., 134.

70. S. L. Catlin, “Cuarta sesión..., op. cit., 124. Debe añadirse que la insistencia de Catlin y Grieder sobre la importancia del patrimonio latinoamericano y la necesidad de un patronazgo de las artes que fuera eficaz suponía una coincidencia con los contenidos de la introducción escrita por ellos para el catálogo de la muestra «Art of Latin America since Independence» (1966, 1-6), donde hablan de manera elogiosa sobre la labor de patronazgo de los gobiernos latinoamericanos decimonónicos y de principios del siglo XX, lo que se interpretaba como una herencia del periodo colonial y la tradición académica

71. Vid. D. Bayón, "Reflexiones sobre un simposio de arte”, Plural, 52, 1/1976, 77-79.

72. O. Paz, Carta personal dirigida a Damián Bayón, en S. Ariztondo (ed.), Damián Bayón. Correspondencia recibida, Granada, 2000, 279. 
frentarse a la desazón y el temor que provocaba el que se les tildara de anti indigenistas o prooccidentales por no seguir la radicalidad de estos planteamientos. "Es la variante latinoamericana -concluía el poeta- del terror de los intelectuales de Occidente a ser considerados occidentales y burgueses"73. Los intelectuales ligados a Plural se habían enfrentado en su momento a estos prejuicios emanados de ideologías fuertes, a las que se había referido el autor mexicano en la apertura del simposio; pero estos posicionamientos estaban más relacionados con la literatura o el pensamiento político y no tanto con la crítica de las artes plásticas, según confesaba en la carta.

Con todo, más significativas resultaban las reflexiones de Paz respecto al arte de vanguardia, un fenómeno que tendía a verlo como finiquitado o agotado en sus posibilidades, algo que, como se vio, solamente Frederico Morais, en sintonía con el pensamiento de Mario Pedrosa, apuntó también en Austin. Paz entendía que el objetivo de la revista Plural, dando a conocer a los nuevos artistas latinoamericanos y las tendencias recientes de la vanguardia, se había cumplido con creces, como se ponía de manifiesto en la exposición organizada para el evento de Austin. Ahora se imponía un cambio en las orientaciones del grupo en torno a esta publicación, toda vez que "el concepto mismo de vanguardia -y diría más: el de arte moderno- está en crisis desde hace mucho tiempo"74. Como se encarga de recordarle a Bayón, sus certezas respecto a este tema ya habían sido expuestas por él a finales de los sesenta y confirmadas en su obra Los hijos del limo (1972). Llegado a este punto de convicciones, lo deseable sería ahondar desde la revista no solamente en el estado de la vanguardia en crisis, tanto en Europa como en América del Norte y Latinoamérica; también en los estudios históricoartísticos latinoamericanos en toda su amplitud, incluyendo un tema tan controvertido como el del arte popular, por el que, como se recordará, la brasileña Aracy Amaral había apostado en la reunión que ha sido objeto de estudio.

\section{Conclusiones}

Las sesiones del simposio celebrado en Austin suponen un momento de gran significado para entender los logros y los límites de la crítica latinoamericana del siglo XX en el periodo previo a la crisis definitiva de la modernidad que abre paso a las nuevas propuestas de autores cuyo protagonismo llenan las dos últimas décadas del siglo y los inicios del siguiente. A diferencia de otros foros de discusión de esos años, como los de Caracas o São Paulo, el evento de Austin destaca no solamente porque se lleva a cabo en territorio norteamericano, sino también por la acentuada diversidad profesional de los participantes (críticos, historiadores del arte, directores de museo, artistas) y la presencia de un plantel notable de expertos norteamericanos que aportan una visión definitivamente plural. Con todo, en el lado latinoamericano se echa en falta a figuras muy influyentes, como son Mario Pedrosa y Romero Brest. La

73. O. Paz, Carta personal..., op. cit., 280.

74. O. Paz, Carta personal..., op. cit., 280. 
presencia silente del cubano Gómez Sicre no evita los comentarios elogiosos de Marta Traba y José Luis Cuevas dirigidos a su figura, comentarios con los que dan a entender la gran deuda que el arte latinoamericano contemporáneo tenía con él como difusor de la idea un arte latinoamericano con personalidad propia ${ }^{75}$.

Como ocurrió en los sucesivos encuentros de críticos y artistas de esta década, el asunto de la identidad se revela como uno de los grandes ejes temáticos a debatir. En el caso de Austin se impone, además, una gran variedad interpretativa. Desde la postura del pintor Tamayo, que entiende la identidad como algo subjetivo e intransferible, pasando por la propuesta de Juan Acha que reivindica una necesaria conceptualización con el fin de generar modelos que permitan entender la diferencia latinoamericana en contraste con los modelos occidentales, pasando por vehemente defensa propuesta por Marta Traba y su arte de la resistencia. En una línea también claramente opuesta a la dependencia cultural y crítica que impone el imperialismo está la de Aracy Amaral y su visión de Latinoamérica como un continente ocupado. Probablemente la mayor debilidad de las posturas radicales de Traba y Amaral radica en que no plantean sus propuestas con el fin de abarcar a una gran variedad de lenguajes artísticos. Si en el caso de Traba, sus ejemplos de arte resistente pasan por la neofiguración renovada de artista muy conocidos ${ }^{76}$, en el de Amaral, la mirada se dirige fundamentalmente hacia los valores del arte popular como esencia diferenciadora de lo propiamente latinoamericano.

El arte brasileño es el gran desconocido por los críticos de la América de habla española a esas alturas del siglo XX, algo que uno de los presentes como Bayón confiesan abiertamente. Por añadidura, los críticos brasileños que participan en este simposio aportan una visión del arte contemporáneo de una indudable singularidad, tanto por lo que se refiere a Aracy Amaral y su ya comentada insistencia en el arte popular, como por las sugerencias de Frederico Morais, que defiende el valor del arte constructivo, tan arraigado en Brasil, como una propuesta viable para el arte de otros países del subcontinente. Sorprende, sin embargo, que en las declaraciones de este crítico no encontremos el reconocimiento a las propuestas abstractas geométricas uruguayas y argentinas, que habían precedido a las brasileñas.

A su vez, al sacar a relucir el concepto de postmodernidad (ideado por Pedrosa), Morais cuestiona el de vanguardia, como ya había hecho en su momento también Octavio Paz desde su particular producción crítica. Sin embargo, no parece que entre los participantes a este simposio semejante certidumbre haya sido asumida. Se sigue hablando de vanguardias como una realidad actuante y sólida, ni mucho menos en crisis. Marta Traba ve una amenaza para el arte latinoamericano, por su inanidad, la importación de tendencias como el happening

75. F. Serviddio señalará, al referirse al simposio de Austin en su estudio sobre la crítica de los setenta que, en contra de estas opiniones sobre Gómez Sicre, el alcance de sus trabajos editoriales y expositivos, más allá de su indudable interés divulgativo, lo que desvelaban era más bien una «imagen de América Latina más como grupo de países con tradiciones nacionales fuertes y diferenciadas que como conjunto en el que se buscaban homogeneizaciones regionales». F. Serviddio, op. cit., 252.

76. Damián Bayón, en el artículo ya citado sobre los resultados del simposio, dejaba ver su poca simpatía hacia el concepto de «resistencia» creado por Traba, «cuando a renglón seguida de declararla se nos da la lista de los elegidos, entre los que figuran una serie de honorables artistas bien establecidos y hasta famosos». Vid. D. Bayón, op. cit., 79. 
o el conceptual, calificadas por Bayón como aburridas y por Traba como payasadas. Como reconoce el primero, no obstante, la visión que se tiene en Brasil nada tiene que ver con estas descalificaciones. En Morais encontramos una valoración especial del conceptual, en el que el artista se vuelve crítico y el crítico se transforma en artista. El contraste con las apreciaciones que sobre estas tendencias se pueden ver en la mayoría de los presentes en el debate no revela tanto una confrontación real a partir de convicciones críticas como un desconocimiento en profundidad de los valores de estas nuevas alternativas de expresión, que solamente en la Argentina habían tenido un cierto eco hasta ese momento.

La distancia que algunos artistas como Tamayo manifiestan hacia la crítica, a la que no le reconocen su capacidad de influencia directa sobre ellos, contrasta con otras valoraciones aireadas en este contexto. Se reconoce la debilidad de una crítica, que, según algunos, como Manrique, tiene mejor perfil académico que divulgativo. Fue especialmente brillante la aportación del artista mexicano Manuel Felguérez, quien superó las limitaciones y prejuicios de Tamayo en este tema, de modo que entendía que la crítica como interpretación se hacía absolutamente necesaria para adentrarse en el universo de la creación artística y superar las dificultades que los diversos lenguajes podían suponer para el público. En clave más bien política, además, el escultor mexicano relaciona la crítica relacionada con el poder con la censura, lo cual lleva directamente al último de los grandes temas del debate en el simposio

El asunto de las relaciones entre arte y política, no previsto inicialmente en el plan del simposio, más allá de algunas consideraciones sobre el proceso fallido del arte revolucionario mexicano, se centra en la experiencia reciente del régimen cubano, tratado por los debatientes desde un punto de vista expectante y positivo. Se le reconoce al castrismo el mérito de no imponer los patrones del realismo socialista y fomentar, sin embargo, los lenguajes modernos a través de las artes reproductivas; también la potenciación del cine. Con la excepción de la un tanto recelosa Dore Ashton, la mayoría de los que intervinieron sobre este asunto (Traba, Bayón, Rita Eder) tuvieron palabras de elogio sobre todo por lo que tenía la política cubana en este ámbito de apertura a un público hasta ahora marginado de la dinámica cultural del país.

En general, la crítica norteamericana implicada en los debates se muestra distante frente a las denuncias que subrayan la dependencia latinoamericana y la presión condicionante del imperialismo de los grandes centros de la cultura occidental. El caso de Duncan es bien sintomático, pero también el de Ashton. En su afán por integrar al arte latinoamericano en el espacio de la modernidad occidental y hacerle partícipe de sus especificidades, esta desconsideraba algunas importantes limitaciones que impedían que semejante integración se viviera como algo posible, al menos como algo pleno. Por encima de todo, estaba la dominante socioeconómica que lastraba a la cultura latinoamericana del momento a una inevitable subalternidad, algo que no impedía su riquísimo desarrollo interno, pero que imposibilitaba un diálogo de tú a tú con los grandes centros del arte internacional.

Con todo, el encuentro de Austin puede considerarse un ejemplo sin igual de las aspiraciones y contradicciones de la crítica latinoamericana del momento, pues si bien esta aspiraba a defender la singularidad del arte del subcontinente, incluso su carácter anticipatorio en algunos casos frente a los modelos centrales, el desarrollo de sus iniciativas en este sentido no hacía sino corroborar, aunque fuese implícitamente, la dependencia o necesidad 
de ese mismo modelo que se criticaba. Como apunta Joaquín Barriendos a este respecto, la finalidad de los latinoamericanismos de la época era la de

sintonizar el arte latinoamericano con la marcha de la historia que le marcaban las vanguardias y neo-vanguardias situadas en Europa y Estados Unidos, esforzándose para ello en dar prueba de sus innovaciones locales, progresos propios y autenticidades. Su finalidad era la de "hacerlo bailar" al compás de la historia por medio de corregir el destiempo y el "incorrecto" emplazamiento de América Latina en el concierto global de la racionalidad civilizatoria occidental ${ }^{77}$

El caso es que la evolución del pensamiento artístico de las últimas décadas, la irrupción del poscolonialismo y los efectos de la globalización rompieron definitivamente con las «jerarquías estéticas que dominaron la disyunción espacial, epistémica y geoestética que separaba y al mismo tiempo interconectaba asimétricamente a Occidente con sus otros» ${ }^{78}$. Por eso, la postura de la nueva crítica surgida entonces, representada de manera muy elocuente por individualidades como Gerardo Mosquera ${ }^{79}$, se caracteriza por marcar una clara distancia con respecto a los paradigmas que habían servido de referencia a los participantes en el simposio de Austin, representantes de una época cultural definitivamente cerrada.

77. J. Barriendos, La idea del arte latinoamericano. Estudios globales del arte, geografías subalternas, regionalismos críticos, Tesis doctoral, Universidad de Barcelona, 2013, 40.

78. J. Barriendos, La idea..., op. cit., 41

79. En este sentido, son esclarecedores sus textos: "Contra el arte latinoamericano", en AA.VV., Seminario Una nueva historia del arte en América Latina, Oaxaca, 1996; "Acerca de la modernidad y del arte: un listado de cuestiones finiseculares", en G. Mosquera (coord.), Adiós identidad: Arte y cultura desde América Latina, Badajoz, 2001, 23-41, y “Contemporary Art in Latin America”, en Phoebe Adler y otros (edts.), Contemporary Art in Latin America, Londres, 2010. 